\title{
Serological and Molecular Evidence of Q Fever in Domestic Ruminants in Bangladesh
}

\author{
Md. Arifur Rahman, ${ }^{1}$ Md. Mahbub Alam, ${ }^{1}$ Md. Aminul Islam, ${ }^{1}$ \\ A. K. Fazlul Haque Bhuiyan, ${ }^{2}$ and A. K. M. Anisur Rahman ${ }^{1}$ \\ ${ }^{1}$ Department of Medicine, Faculty of Veterinary Science, Bangladesh Agricultural University (BAU), Mymensingh 2202, Bangladesh \\ ${ }^{2}$ Department of Animal Breeding and Genetics, Faculty of Animal Husbandry, BAU, Mymensingh 2202, Bangladesh
}

Correspondence should be addressed to A. K. M. Anisur Rahman; arahman_med@bau.edu.bd

Received 3 February 2016; Accepted 7 April 2016

Academic Editor: Giuliano Bettini

Copyright ( 2016 Md. Arifur Rahman et al. This is an open access article distributed under the Creative Commons Attribution License, which permits unrestricted use, distribution, and reproduction in any medium, provided the original work is properly cited.

\begin{abstract}
The objective of this study was to know the herd and animal level prevalence of $\mathrm{Q}$ fever in domestic ruminants in some selected districts in Bangladesh. Randomly collected 111 bulk milk and 94 sera samples of cattle, sheep, and goats were tested by indirect ELISA (iELISA). DNA extracted from 23 aborted fetal membranes was analyzed by real time (rt) PCR. The positive cut-off value of iELISA in bulk milk and individual animal sera was $\geq 30 \%$ and $\geq 40 \%$, respectively. The overall herd level prevalence of Q fever in dairy cattle was $15.6 \%$. The prevalence of Q fever in dairy cattle was significantly higher in Sirajganj in comparison to Satkhira District $(P<0.01)$. The overall seroprevalence of $Q$ fever in domestic ruminants was $5.06 \%$. Although statistically insignificant, the seroprevalence of $Q$ fever was relatively higher in sheep (9.52\%) in comparison to goats (3.33\%) and cattle (3.57\%). Out of 23 aborted fetal membranes, only one sheep placenta was positive in rt PCR. Q fever is present in all of the three important species of domestic ruminants in Bangladesh. It may have some role in sheep abortion as the seroprevalence is relatively higher and also one sheep placenta is $\mathrm{rt}$ PCR positive.
\end{abstract}

\section{Introduction}

Q (for Query) fever is a ubiquitous zoonosis caused by an obligate intracellular bacterium Coxiella $(C$.) burnetii. It has been reported from all over the world except Antarctica and possibly New Zealand $[1,2]$. The primary reservoirs of $C$. burnetii are cattle, sheep, and goats. However, the infection has been reported in other mammals (humans, cats, dogs, rodents, rabbits, horses, swine, camels, water buffalo, and marine mammals), ticks and other arthropods, birds, fish, and reptiles $[3,4]$. The common manifestations of $\mathrm{Q}$ fever in ruminants are abortion, stillbirth, premature delivery, and delivery of weak offspring [2]. Indeed these clinical manifestations are usually observed in sheep and goats and Q fever is mostly asymptomatic in cattle. Clinically infected cows may develop infertility, metritis, and mastitis [5].

In humans, $\mathrm{Q}$ fever is mostly asymptomatic but may be responsible for acute or chronic disease conditions such as influenza-like illness, pneumonia, hepatitis, meningoencephalitis, myocarditis, endocarditis, and chronic fatigue syndrome in persistently infected patients and may contribute to abortion and stillbirth in pregnant women $[2,6]$.

Diagnosis of $\mathrm{Q}$ fever in animals is based on detection of bacteria, bacterial DNA, or antibodies [7]. Although these bacteria can grow in axenic (host cell-free) media, isolation is time consuming and hazardous for the laboratory workers [8]. In addition, Q fever isolation techniques require a Biosafety Level 3 Laboratory (BSL-3). Mostly, C. burnetii exposure in animals can be screened indirectly by serological tests. The CFT (OIE recommended test) and ELISA (EU recommended test) are the two most commonly used serological tests in this purpose. However, CFT protocol is complex and fails to detect antibodies in sheep or goats [9]. The ELISA is reported to be highly sensitive and specific for the diagnosis of $\mathrm{Q}$ fever [10]. Moreover, ELISA can be used to 
detect antibodies in bulk milk and individual animal serum. The bacterial DNA can be detected by using PCR [11].

Although $\mathrm{Q}$ fever is present worldwide, its status in animals, humans, arthropods, birds, wild animals, and other reservoirs in Bangladesh is not known except one report on serological evidence in cattle and goats [12]. Nevertheless, the reproductive diseases in dairy cattle [13-15] are endemic in Bangladesh. So the objectives of this paper are to determine the herd level prevalence of $\mathrm{Q}$ fever in dairy cattle and goats, to estimate the animal level prevalence of $\mathrm{Q}$ fever in cattle, sheep, and goats originated from herds having previous history of abortion, and to detect C. burnetii DNA from aborted fetal membranes of cattle, goat, and sheep.

\section{Materials and Methods}

2.1. Milk Samples. This study used milk samples from two previous studies, which were undertaken in the Department of Medicine, BAU, Mymensingh 2202. In one study, 399 randomly collected bulk milk samples were examined for somatic cell count from where 94 samples were used in this study. The history of reproductive failure in the selected dairy herds was not known. In another study, 17 milk ring test positive samples were sent to Belgium for isolation of Brucella spp., which were also used for this study. The districts of Bangladesh included in this study are shown in Figure 1.

2.2. Serum Sample Collection. Serum samples were collected from a serum bank in the Department of Medicine, BAU, Mymensingh. Those samples were randomly collected to study brucellosis in cattle, sheep, and goats in different districts of Bangladesh in 2007 and 2008 [16]. Ninety-four (94) serum samples were collected from 40 herds of the Mymensingh and Sherpur Districts out of 58 having some abortion (known from the owners) in the last year.

2.3. DNA Samples of Placentas. Twenty-three DNA samples (5 from cattle, 10 from goats, and 8 from sheep) extracted from aborted fetal membranes for the detection of Brucella spp. were also used in this study. DNA was extracted using the DNeasy spin column kit (QIAGEN) according to the manufacturer's protocol.

2.4. Herd and Animal Level Data Collection. Animal level data on age, breed, sex, and pregnancy status and herd level data on herd size, herd composition, and location of the herd were collected from available database of serum samples.

For milk samples, the location of the farm and number of lactating cows in herd were collected from the bovine mastitis database.

\subsection{Indirect ELISA Test}

2.5.1. Preparation of Milk and Sera Samples. The milk and sera samples were prepared according to the instructions of commercial kit. In brief, 10 milliliters of milk from each selected herd was collected for testing antibody against $C$. burnetii exposure. The samples were centrifuged and the nonfat fraction was stored at $-20^{\circ} \mathrm{C}$ until tested for antibodies against $C$. burnetii. Before testing, herd milk samples were prepared at $1: 5$ dilution using diluted $(1: 10)$ wash solution. Sera of the selected animals were removed from the serum bank and prepared at 1:400 dilution by using diluted wash solution.

2.5.2. Test Procedure. All reagents were taken into $18-26^{\circ} \mathrm{C}$ before use. The reagents were mixed by shaking gently. All samples were tested in duplicate and the optical densities (OD) of the samples were averaged and corrected by subtracting the OD of the negative control. Both milk and serum based tests were performed using the commercial CHEKIT Q Fever Antibody ELISA Test Kit (IDEXX, Liebefeld-Bern, Switzerland) based on C. burnetii inactivated phase 1 and phase 2 antigens [10]. The positive cut-off value ( $\mathrm{S} / \mathrm{P}$ ratio) of iELISA in bulk milk and individual animal sera was $\geq 30 \%$ and $\geq 40 \%$, respectively.

2.6. Real Time PCR. The real time (rt) PCR assay was performed using a $7500 \mathrm{rt} \mathrm{PCR} \mathrm{System} \mathrm{(Applied} \mathrm{Biosystems).}$ Samples were considered positive with a cycle threshold $(\mathrm{Ct})$ $<40$ [17]. It was performed in Veterinary Agrochemical Research Centre (CODA-CERVA) in Brussels, Belgium.

2.7. Statistical Analysis. The association of herd and animal level factors with Q fever prevalence was analyzed by $\chi^{2}$ test using R 3.1.0 (The R Foundation for Statistical Computing 2014).

\section{Results}

3.1. Descriptive Statistics. The serum samples were collected from 40 herds where there was history of abortion in any of the three domestic ruminant species in the last year. The herd size varied from 1 to 20 with a median of 3 animals. Thirteen herds consisted of only cattle, 13 of only goats, 8 of both cattle and goats, and 6 of only sheep. In $55.0 \%$ (22/40) herd's aborted materials were disposed by burial but in the rest of the herds the materials were thrown away in the field or in nearby water bodies. About 35\% (14/40) farmers were found to keep sheep $(7.5 \%)$ or goats $(27.5 \%)$ inside their house at night.

The age of cattle varied from 4 months to 12 years with a median of 6 years. The range and median age of goats and sheep, respectively, were 2.5 months to 4 years and 2 years, 1 month to 4 years and 8 months. Among cattle $82.0 \%$ were female and indigenous and all of the sheep were indigenous and $74.2 \%$ of them were female but $80.0 \%$ and $94.0 \%$ goats were female and Black Bengal breed type, respectively. The range of positive $\mathrm{S} / \mathrm{P}$ value in cattle herds was 41.4 to 123.0.

3.2. Herd Level Prevalence of $Q$ Fever in Dairy Cattle. A summary of ELISA test results on the presence of $C$. burnetii antibodies in herd milk is presented in Table 1. An overall herd level prevalence of Q fever in dairy cattle was $15.6 \%$ (95\% Confidence Interval (CI): 9.4-23.8) (Table 1). The distribution of Q fever in dairy herds is shown in Table 2. The prevalence of Q fever was significantly higher in Sirajganj 


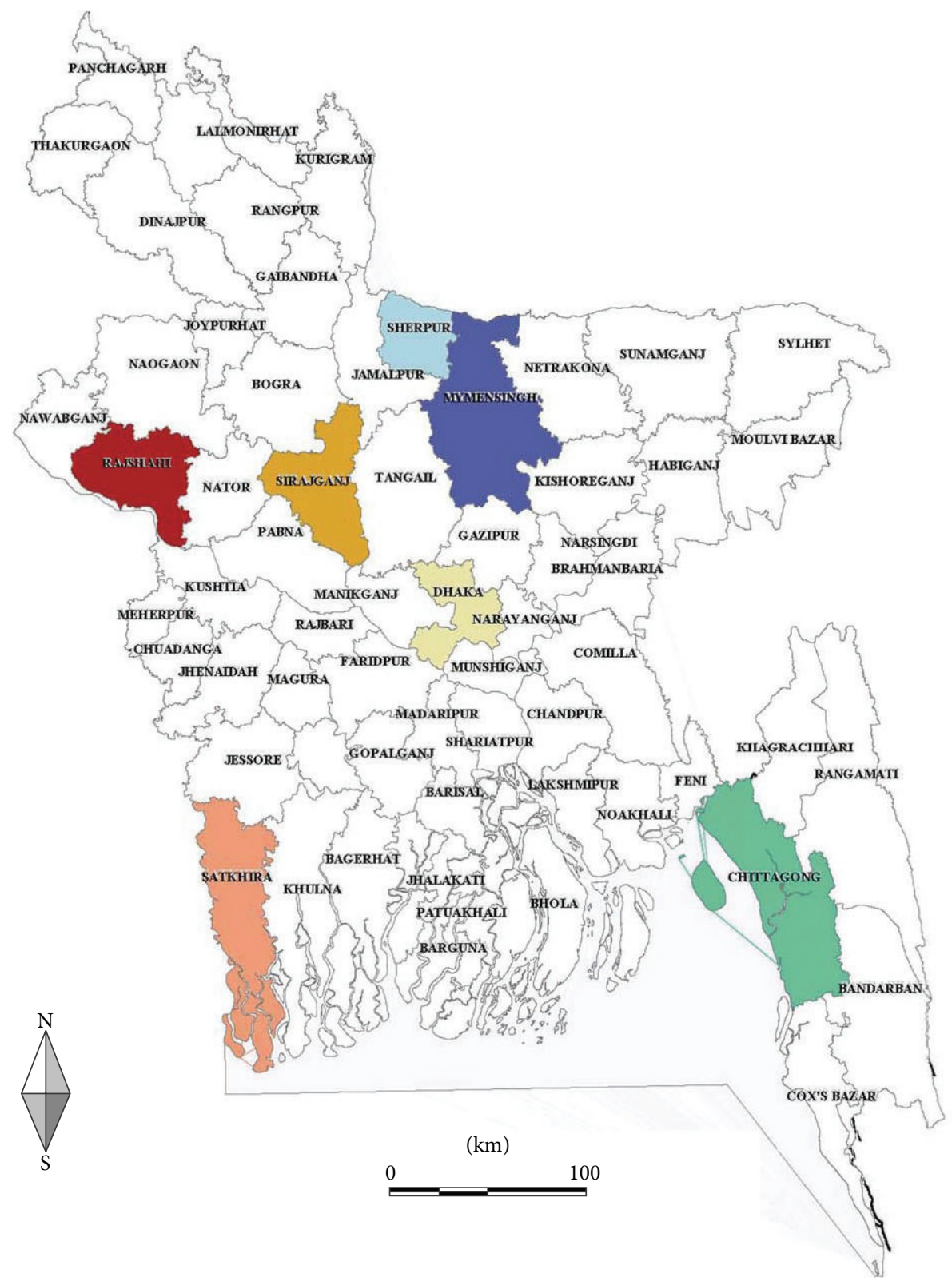

Q fever study areas

Seroprevalence $11.1 \%$ in goats

Seroprevalence $8.3 \%$ and $9.5 \%$ in cattle and sheep, respectively

Herd level prevalence $7.1 \%$

Herd level prevalence $10.1 \%$

Government goat farm positive and a sheep placenta of BLRI sheep farm PCR positive

Herd level prevalence $34.6 \%$

Bulk milk of government goat farm positive

Figure 1 
TABLE 1: Summary of iELISA tests results on the presence of Coxiella burnetii antibodies (S/P values) in milk samples.

\begin{tabular}{lccccc}
\hline Test result & Number of herds/flocks & Apparent prevalence & $95 \%$ CI & Range of S/P values (\%) & Mean S/P values (\%) \\
\hline Positive $(\mathrm{S} / \mathrm{P} \geq 30 \%)$ & 17 (cattle) & $15.6 \%$ & $9.4-23.8$ & $41.4-123.0$ & 81.3 \\
Negative $(\mathrm{S} / \mathrm{P}<30 \%)$ & 92 & $84.4 \%$ & $76.2-90.6$ & $0-25.9$ & 5.6 \\
Positive $(\mathrm{S} / \mathrm{P} \geq 30 \%)$ & 2 (goats) $^{*}$ & & & 421.6 and 424.2 & \\
\hline
\end{tabular}

${ }^{*}$ Both goat flocks were positive; CI: Confidence Interval.

TABLE 2: Distribution of herd level prevalence of Q fever based on iELISA using bulk milk.

\begin{tabular}{|c|c|c|c|c|c|}
\hline Variable & Tested & Positive (>40\%) & Prevalence & $95 \% \mathrm{CI}$ & $\begin{array}{l}\chi^{2} \text { test } \\
P \text { value }\end{array}$ \\
\hline District & & & & & $<0.01$ \\
\hline Satkhira & 28 & 2 & 7.1 & $0.9-23.5$ & \\
\hline Chittagong & 55 & 6 & 10.9 & $4.1-22.2$ & \\
\hline Sirajganj & 26 & 9 & 34.6 & $17.2-55.6$ & \\
\hline Number of lactating cows & & & & & 1 \\
\hline$>5$ & 22 & 3 & 13.6 & $2.9-34.9$ & \\
\hline 1 to 5 & 87 & 14 & 16.1 & $9.1-15.5$ & \\
\hline Breed composition & & & & & 0.29 \\
\hline Sahiwal cross & 18 & 2 & 11.1 & $1.4-34.7$ & \\
\hline Friesian cross & 73 & 10 & 13.7 & $6.8-23.8$ & \\
\hline Both & 18 & 5 & 27.8 & $9.7-53.5$ & \\
\hline
\end{tabular}

The other two bulk milk samples were collected from two government goat farms in Savar, Dhaka, and Rajshahi Districts; CI: Confidence Interval.

(34.6\%) in comparison to Satkhira District $(P<0.01)$. Although statistically insignificant, the prevalence of $Q$ fever was relatively higher in herds having only Friesian cross (13.7\%) and both Sahiwal and Friesian breed together (27.8\%) in comparison to Sahiwal cross.

3.3. Seroprevalence of Q Fever in Cattle, Goats, and Sheep. The summary of ELISA test results on the presence of C. burnetii antibodies in serum samples is provided in Table 3. Out of 94 sera samples tested, the ages of 15 (10 sheep and 5 goats) animals were below six months (two seropositive sheep), which were excluded from the result in estimating seroprevalence (maternal immunity). The overall seroprevalence of Q fever in domestic ruminants was 5.06\% (95\% CI: 1.63-13.14). Three point seven nine percent (3.79\%) sera samples were Q fever suspect and $91.13 \%$ were Q fever negative. The range of positive S/P value was 42.70 to $49.80 \%$. The distribution of $\mathrm{Q}$ fever seroprevalence in domestic ruminants is shown in Table 4. The seroprevalence of Q fever was found to be higher in sheep (9.52\%, 95\% CI: 1.67-31.83) in comparison to goat (3.33\%, 95\% CI: 0.17-19.05) and cattle (3.57\%, 95\% CI: $0.18-$ 20.24) but it was statistically insignificant. The seroprevalence of $\mathrm{Q}$ fever varied according to sex, pregnancy status, and study areas but none was significant statistically.

The demographic characteristics of the four Q fever seropositive domestic ruminants are shown in Table 5. Both seropositive sheep were from the same location (Unions/SubUpazila of Mymensingh Sadar Upazila/subdistrict).
3.4. Real Time PCR Result. Coxiella burnetii DNA was detected from only one sheep placenta. The remaining 22 samples were negative.

\section{Discussion}

In this study the herd level prevalence of Q fever in cattle based on bulk milk and animal level seroprevalence of $Q$ fever in cattle, goats, and sheep were estimated by using indirect ELISA test. The overall prevalence of $\mathrm{Q}$ fever in bulk cow milk was $15.6 \%$ indicating that $Q$ fever is an existing disease in dairy cattle population in Bangladesh. The herds under study were originated from major milk pockets of Bangladesh like Sirajganj, Chittagong, and Satkhira Districts (Figure 1). The sample size was very small and the sample does not represent the dairy herds of Bangladesh. It was also a limitation of this study. Due to the lack of fund it was not possible to include more samples in this study. So the herd level prevalence of $\mathrm{Q}$ fever we obtained may not represent the true status of this disease in dairy herds of the study areas. A widely variable and much higher herd level prevalence of $\mathrm{Q}$ fever (57.8 to $78.6 \%)$ was reported from different corners of the world [18-21]. Dairy cattle are usually chronically infected with Q fever and shed C. burnetii in the milk [22]. It is also stated that chronically infected dairy cattle are the most important source of human infection [1]. Another important source of human infection is the manipulation of fetus and its fluids and placentas from aborted small ruminants without safety 
TABLE 3: Summary of iELISA tests results on the presence of Coxiella burnetii antibodies (S/P values) in serum samples.

\begin{tabular}{lccccc}
\hline Test result & Number & Prevalence (\%) & 95\% Confidence Interval & Range of S/P values (\%) & Mean S/P values (\%) \\
\hline Positive $(\mathrm{S} / \mathrm{P} \geq 40 \%)$ & 4 & 5.06 & $1.63-13.14$ & $42.70-49.80$ & 45.35 \\
Suspect $(30 \% \leq \mathrm{S} / \mathrm{P}<40 \%)$ & 3 & 3.79 & $0.98-11.45$ & $30.10-34.50$ & 32.40 \\
Negative $(\mathrm{S} / \mathrm{P}<30 \%)$ & 72 & 91.13 & $82.04-96.06$ & $0-29.80$ & 5.13 \\
\hline
\end{tabular}

TABLE 4: The distribution of seroprevalence of $Q$ fever in domestic ruminants.

\begin{tabular}{lcccc}
\hline Variable & Tested & Positive & Prevalence $(95 \% \mathrm{CI})$ & $\begin{array}{c}\chi^{2} \text { test } \\
P \text { value }\end{array}$ \\
\hline Species & & & & 0.55 \\
Cattle & 28 & 1 & $3.57(0.18-20.24)$ & \\
Sheep & 21 & 2 & $9.52(1.67-31.83)$ & \\
Goats & 30 & 1 & $3.33(0.17-19.05)$ & \\
Sex & & & & 1.00 \\
Male & 15 & 1 & $6.67(0.34-33.96)$ & \\
Female & 64 & 3 & $4.69(1.22-13.96)$ & \\
Pregnancy & & & & 0.63 \\
No & 38 & 1 & $2.63(0.14-15.43)$ & \\
Yes & 26 & 2 & $7.69(1.34-26.59)$ & \\
Male & 15 & 1 & $6.67(0.34-33.96)$ & \\
District & & & & \\
Sherpur & 25 & 1 & $4.0(0.21-22.32)$ & \\
Cattle & 16 & 0 & $0\left(0-24.07^{*}\right)$ & \\
Sheep & 0 & 0 & & \\
$\quad$ Goats & 9 & 1 & $11.11(0.58-49.33)$ & \\
Mymensingh & 54 & 3 & $5.56(1.44-16.34)$ & \\
Cattle & 12 & 1 & $8.33(0.44-40.25)$ & \\
Sheep & 21 & 2 & $9.52(1.67-31.83)$ & \\
$\quad$ Goats & 21 & 0 & $0\left(0-19.24^{*}\right)$ & \\
\hline
\end{tabular}

CI: Confidence Interval; ${ }^{*} 97.5 \%$ Confidence Interval.

protection measures. As Q fever is a zoonosis and it exists in animals of Bangladesh it is also supposed to be present in humans. Due to lack of reporting, awareness, and nonspecific influenza-like symptoms of this disease in humans, it may be overlooked and remained undiagnosed in human diagnostic laboratories. Due to lack of reporting from animals, the physicians are also unaware about this disease in humans. As a result, physicians usually do not refer flu-like cases for Q fever diagnosis. Both in humans and in animals, inhalation of bacteria present in the environment is the main route of infection. So dairy workers, animal caretakers, and pyrexia of unknown origin cases should be regularly tested for Q fever. Moreover, consumption of contaminated raw milk may produce infection in humans [1]. Indeed, the Bangladeshi population seldom ingests the raw milk.

We have tested only bulk milk, which does not allow identification of individual cows infected with Q fever. However, it is very useful for screening herds under disease surveillance system. A large epidemiologic study including representative dairy herds of Bangladesh will help to reveal the herd level status of this disease in Bangladesh. Out of three study areas, significantly higher prevalence of Q fever was found in dairy herds of Sirajganj than Satkhira District. The cattle management system in Sirajganj area slightly varies from that of other parts of Bangladesh. In the dry season, the cattle graze freely and remain in the pasture ("Bathan") for almost six months (December to May). As a result, a lot of intermingling among cattle of different owners occurs during that period. Intermixing of cattle from different owners may facilitate the transmission of infection in dairy cattle herds of this area. In some herd, presence of sheep is also noticed in that period. Environment conditions in dry season could play a role in the survival of the bacteria and facilitate the transmission between animals as well. Similarly, higher prevalence of Q fever in loose housing system was also reported by Paul et al. [10]. Capuano et al. [23] also reported relatively higher seroprevalence of $\mathrm{Q}$ fever in herds housed in winter but turned out in spring than those housed permanently. Like other infectious diseases, Q fever was reported to be significantly associated with increased herd size $[23,24]$. In this study, the prevalence of $Q$ fever in contrast was a bit higher in smaller herds. However, the difference was not significant statistically. The prevalence of $\mathrm{Q}$ fever was relatively higher in herds having Friesian cross and in herd containing both Sahiwal and Friesian breed together although the difference was not significant statistically. Other authors had also reported significantly higher level of $\mathrm{Q}$ fever prevalence in Holstein breed $[10,23]$.

We have observed relatively higher seroprevalence of Q fever in sheep than cattle and goats. Similar observations were also reported by other authors $[25,26]$. The prevalence of $\mathrm{Q}$ fever was reported to be significantly higher with the age of the animals [27-29]. We have also observed that the age of the seropositive animals is $\geq 10$ months.

In our study, serum samples of the animals were originated from herds where there was history of abortion in previous year. Out of four seropositive cases two were in sheep indicating that $\mathrm{Q}$ fever might have some role in sheep abortion. Our rt PCR result also supports this hypothesis. An rt PCR Q fever positive result in the placenta means a contact with the bacteria. To confirm an abortion caused by Coxiella burnetii is necessary to detect histopathology lesions in the aborted fetus and placenta. Significantly higher seroprevalence of $\mathrm{Q}$ fever in sheep had also been reported by Berri et al. [30]. The immunosuppressive effects of pregnancy may be responsible for the increased multiplication of the organism in the placenta and thereby the higher seroprevalence [31].

It is revealed from this study that Q fever is present in all of the three important domestic ruminant species in Bangladesh. It may have some role in sheep abortion as 
TABLE 5: Characteristics of the four Q fever seropositive domestic ruminants.

\begin{tabular}{|c|c|c|c|c|c|c|c|}
\hline Farmer ID & Area & Species & Age & Breed & Sex & Body weight & $\mathrm{S} / \mathrm{P}$ value $(\%)$ \\
\hline $\mathrm{Fa} 50$ & Sirta, Mymensingh Sadar & Cattle & 6 years & Indigenous & Female & 200 & 42.7 \\
\hline Fa 268 & Noyabil, Sherpur & Goat & 1 year & Black Bengal & Female & 6 & 49.8 \\
\hline Fa 543 & Buror Chor, Mymensingh Sadar & Sheep & 10 months & Indigenous & Male entire & 12 & 43.4 \\
\hline $\mathrm{Fa} 548$ & Buror Chor, Mymensingh Sadar & Sheep & 1.5 years & Indigenous & Female & 18 & 45.5 \\
\hline
\end{tabular}

the seroprevalence is relatively higher and one sheep placenta is rt PCR positive.

\section{Competing Interests}

The authors declare that they have no competing interests.

\section{Acknowledgments}

This research work was funded by the Seed Bull Production Project (SPGR fund) in the Department of Animal Breeding and Genetics, BAU, and the NST Authority. The authors are grateful to Professor Dr. Md. Taohidul Islam, Department of Medicine, BAU, Mymensingh, for providing bulk milk samples and to Dr. David Fretin of Veterinary Agrochemical Research Centre, Brussels, Belgium, for the support on real time PCR.

\section{References}

[1] M. Maurin and D. Raoult, "Q fever," Clinical Microbiology Reviews, vol. 12, no. 4, pp. 518-553, 1999.

[2] E. Angelakis and D. Raoult, "Q fever," Veterinary Microbiology, vol. 140, no. 3-4, pp. 297-309, 2010.

[3] B. Babudieri, "Q fever: a zoonosis," Advances in Veterinary Science, vol. 5, pp. 81-182, 1959.

[4] S. R. Porter, G. Czaplicki, J. Mainil, R. Guattéo, and C. Saegerman, "Q fever: current state of knowledge and perspectives of research of a neglected zoonosis," International Journal of Microbiology, vol. 2011, Article ID 248418, 22 pages, 2011.

[5] H. To, K. K. Htwe, N. Kako et al., "Prevalence of Coxiella burnetii infection in dairy cattle with reproductive disorders," Journal of Veterinary Medical Science, vol. 60, no. 7, pp. 859-861, 1998.

[6] M. J. Wildman, E. G. Smith, J. Groves, J. M. Beattie, E. O. Caul, and J. G. Ayres, "Chronic fatigue following infection by Coxiella burnetii (Q fever): ten-year follow-up of the 1989 UK outbreak cohort," Quarterly Journal of Medicine, vol. 95, no. 8, pp. 527538, 2002.

[7] A. Rodolakis, "Q fever, state of art: epidemiology, diagnosis and prophylaxis," Small Ruminant Research, vol. 62, no. 1-2, pp. 121$124,2006$.

[8] A. Omsland, T. Hackstadt, and R. A. Heinzen, "Bringing culture to the uncultured: Coxiella burnetii and lessons for obligate intracellular bacterial pathogens," PLoS Pathogens, vol. 9, no. 9, Article ID e1003540, 2013.

[9] E. Kováčová, J. Kazár, and A. Šimková, “Clinical and serological analysis of a Q fever outbreak in western Slovakia with fouryear follow-up," European Journal of Clinical Microbiology and Infectious Diseases, vol. 17, no. 12, pp. 867-869, 1998.

[10] S. Paul, J. F. Agger, B. Markussen, A.-B. Christoffersen, and J. S. Agerholm, "Factors associated with Coxiella burnetii antibody positivity in Danish dairy cows," Preventive Veterinary Medicine, vol. 107, no. 1-2, pp. 57-64, 2012.

[11] E. Rousset, V. Duquesne, P. Russo, and M. F. Aubert, "Q fever," in Manual of Diagnostic Tests and Vaccines for Terrestrial Animals, World Organisation for Animal Health (OIE), Paris, France, 2010.

[12] N. Haider, M. S. Rahman, S. U. Khan et al., "Serological evidence of Coxiella burnetii infection in cattle and goats in Bangladesh," EcoHealth, vol. 12, no. 2, pp. 354-358, 2015.

[13] M. A. S. Talukder, M. A. M. Y. Khandoker, M. G. M. Rahman, M. R. Islam, and M. A. A. Khan, "Reproductive problems of cow at Bangladesh Agricultural University Dairy Farm and possible remedies," Pakistan Journal of Biological Sciences, vol. 8, pp. 1561-1567, 2005.

[14] A. Khair, M. M. Alam, A. K. M. A. Rahman, M. T. Islam, A. Azim, and E. H. Chowdhury, "Incidence of reproductive and production diseases of cross-bred dairy cattle in Bangladesh," Bangladesh Journal of Veterinary Medicine, vol. 11, no. 1, pp. 3136, 2014.

[15] M. A. S. Sarker, M. Aktaruzzaman, A. K. M. A. Rahman, and M. S. Rahman, "Retrospective study of clinical diseases and disorders of cattle in Sirajganj district in Bangladesh," Bangladesh Journal of Veterinary Medicine, vol. 11, no. 2, pp. 137-144, 2014.

[16] A. K. M. A. Rahman, C. Saegerman, D. Berkvens et al., "Bayesian estimation of true prevalence, sensitivity and specificity of indirect ELISA, Rose Bengal Test and Slow Agglutination Test for the diagnosis of brucellosis in sheep and goats in Bangladesh," Preventive Veterinary Medicine, vol. 110, no. 2, pp. 242-252, 2013.

[17] S. Boarbi, M. Mori, E. Rousset, K. Sidi-Boumedine, M. Van Esbroeck, and D. Fretin, "Prevalence and molecular typing of Coxiella burnetii in bulk tank milk in Belgian dairy goats, 20092013," Veterinary Microbiology, vol. 170, no. 1-2, pp. 117-124, 2014.

[18] J. F. Agger, A.-B. Christoffersen, E. Rattenborg, J. Nielsen, and J. S. Agerholm, "Prevalence of Coxiella burnetii antibodies in Danish dairy herds," Acta Veterinaria Scandinavica, vol. 52, article 5, 2010.

[19] J. Muskens, E. Van Engelen, C. Van Maanen, C. Bartels, and T. J. G. M. Lam, "Prevalence of Coxiella burnetii infection in Dutch dairy herds based on testing bulk tank milk and individual samples by PCR and ELISA," Veterinary Record, vol. 168, no. 3, p. 79, 2011.

[20] G. Czaplicki, J.-Y. Houtain, C. Mullender et al., "Apparent prevalence of antibodies to Coxiella burnetii ( $\mathrm{Q}$ fever) in bulk tank milk from dairy herds in southern Belgium," The Veterinary Journal, vol. 192, no. 3, pp. 529-531, 2012.

[21] I. Astobiza, F. Ruiz-Fons, A. Piñero, J. F. Barandika, A. Hurtado, and A. L. García-Pérez, "Estimation of Coxiella burnetii prevalence in dairy cattle in intensive systems by serological and molecular analyses of bulk-tank milk samples," Journal of Dairy Science, vol. 95, no. 4, pp. 1632-1638, 2012. 
[22] G. H. Lang, "Q fever: an emerging public health concern in Canada," Canadian Journal of Veterinary Research, vol. 53, no. 1, pp. 1-6, 1989.

[23] F. Capuano, M. C. Landolfi, and D. M. Monetti, "Influence of three types of farm management on the seroprevalence of $\mathrm{Q}$ fever as assessed by an indirect immunofluorescence assay," Veterinary Record, vol. 149, no. 22, pp. 669-671, 2001.

[24] E. D. Ryan, M. Kirby, D. M. Collins, R. Sayers, J. F. Mee, and T. Clegg, "Prevalence of Coxiella burnetii (Q fever) antibodies in bovine serum and bulk-milk samples," Epidemiology and Infection, vol. 139, no. 9, pp. 1413-1417, 2011.

[25] M. Khalili and E. Sakhaee, "An update on a serologic survey of Q fever in domestic animals in Iran," The American Journal of Tropical Medicine and Hygiene, vol. 80, no. 6, pp. 1031-1032, 2009.

[26] F. Ruiz-Fons, I. Astobiza, J. F. Barandika et al., "Seroepidemiological study of $\mathrm{Q}$ fever in domestic ruminants in semiextensive grazing systems," BMC Veterinary Research, vol. 6, article 3, 2010.

[27] A. L. García-Pérez, I. Astobiza, J. F. Barandika, R. Atxaerandio, A. Hurtado, and R. A. Juste, "Short communication: investigation of Coxiella burnetii occurrence in dairy sheep flocks by bulk-tank milk analysis and antibody level determination," Journal of Dairy Science, vol. 92, no. 4, pp. 1581-1584, 2009.

[28] E. Kennerman, E. Rousset, E. Gölcü, and P. Dufour, "Seroprevalence of Q fever (coxiellosis) in sheep from the Southern Marmara region, Turkey," Comparative Immunology, Microbiology and Infectious Diseases, vol. 33, no. 1, pp. 37-45, 2010.

[29] S. Esmaeili, F. B. Amiri, and E. Mostafavi, "Seroprevalence survey of Q fever among sheep in northwestern Iran," VectorBorne and Zoonotic Diseases, vol. 14, no. 3, pp. 189-192, 2014.

[30] M. Berri, A. Souriau, M. Crosby, and A. Rodolakis, "Shedding of Coxiella burnetii in ewes in two pregnancies following an episode of Coxiella abortion in a sheep flock," Veterinary Microbiology, vol. 85, no. 1, pp. 55-60, 2002.

[31] K. Polydorou, "Q fever in Cyprus: a short review," The British Veterinary Journal, vol. 137, no. 5, pp. 470-477, 1981. 

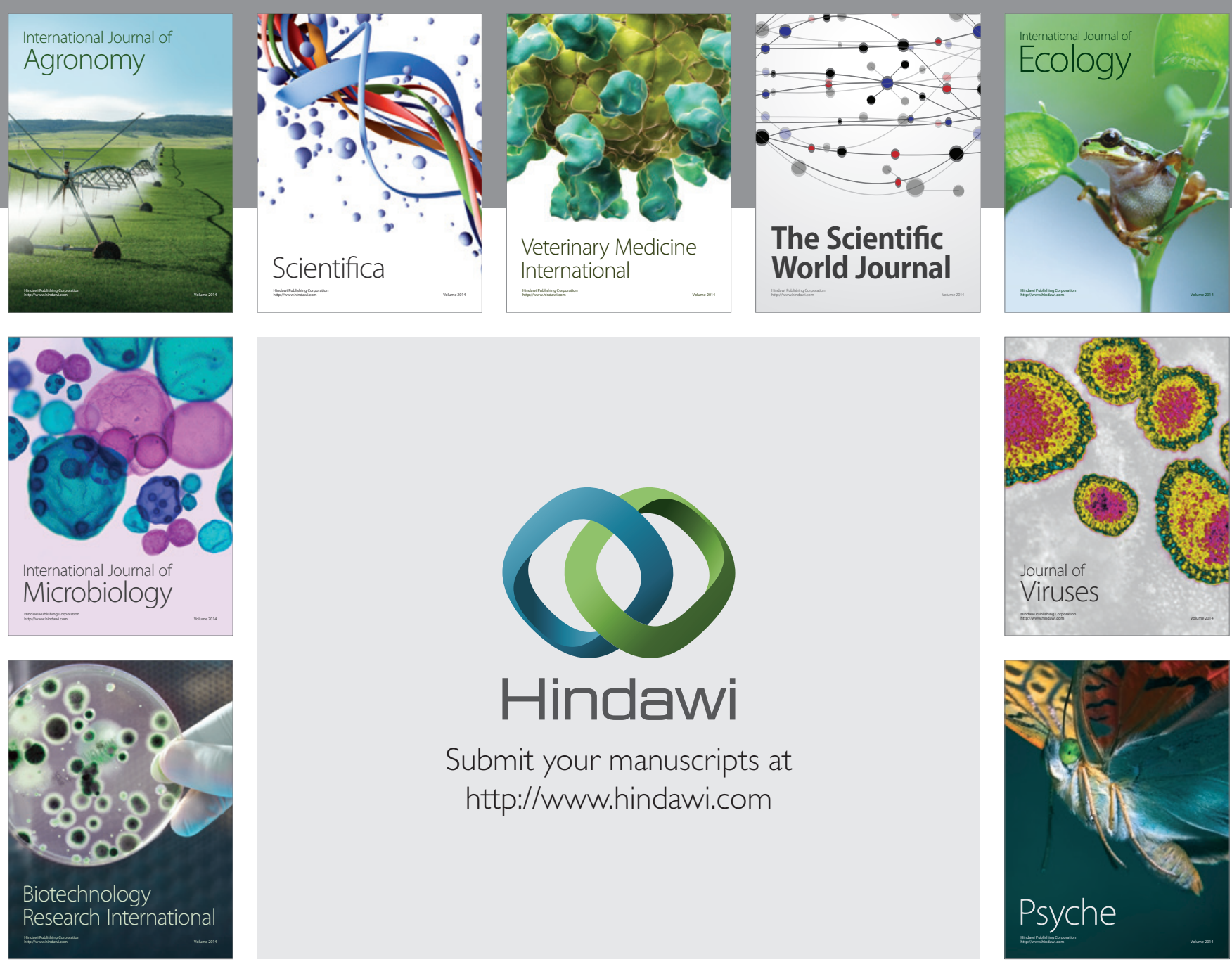

Submit your manuscripts at

http://www.hindawi.com
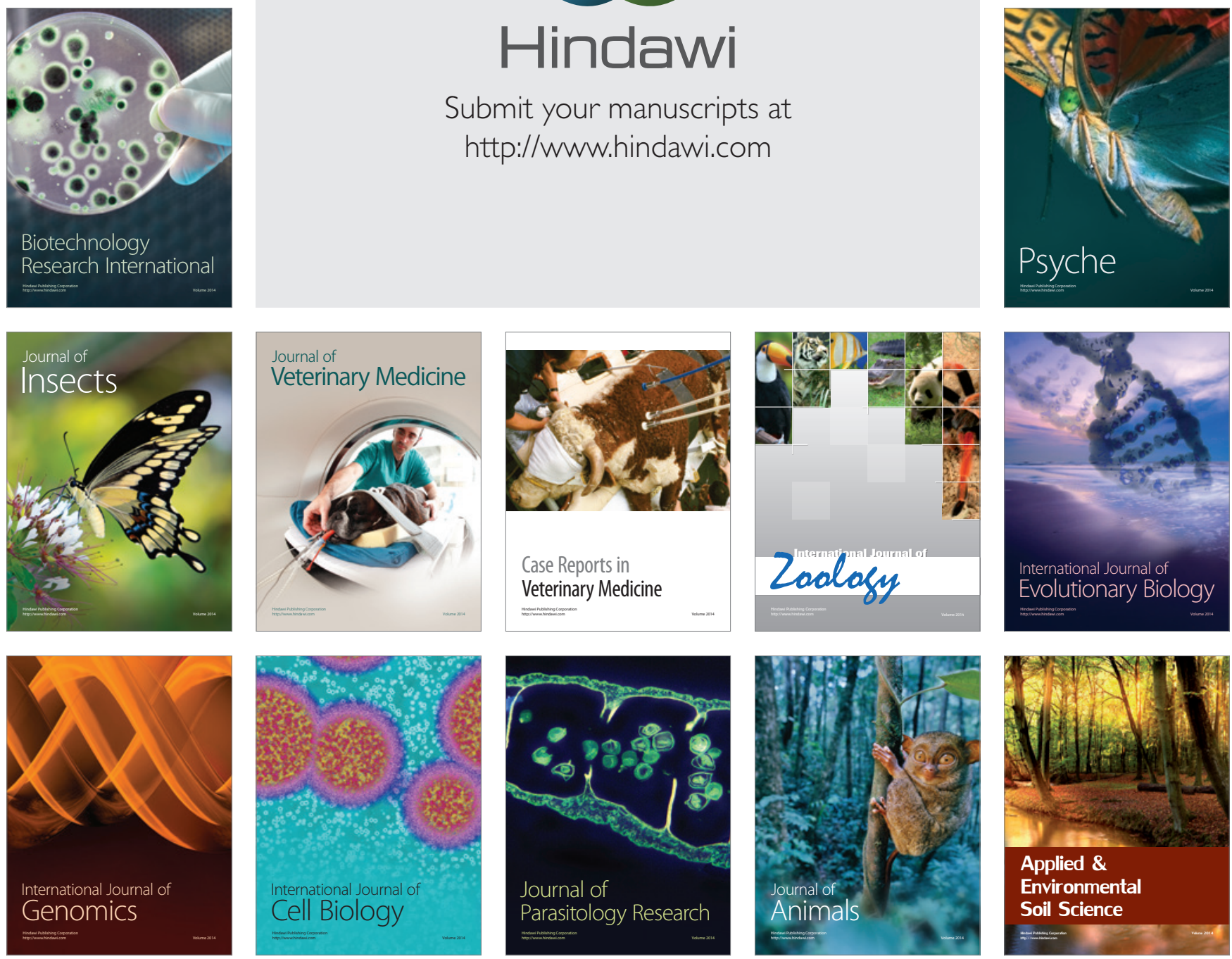